\title{
A Review of Observations Made on Select Parameters of the Camel Immune System
}

\author{
Eugene H. Johnson*, Khalid R. Al-Habsi, \\ and Rashid M. Al-Busaidi \\ Department of Animal and Veterinary Sciences, College of Agricultural and Marine Sciences, \\ Sultan Qaboos University, P.O. Box 34, Al-Khod 123, Sultanate of Oman
}

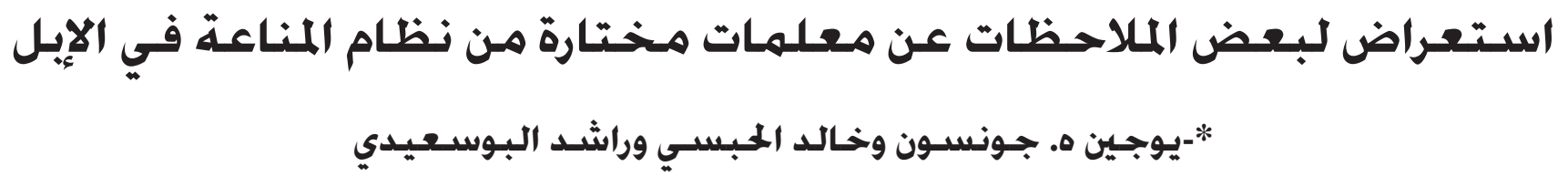

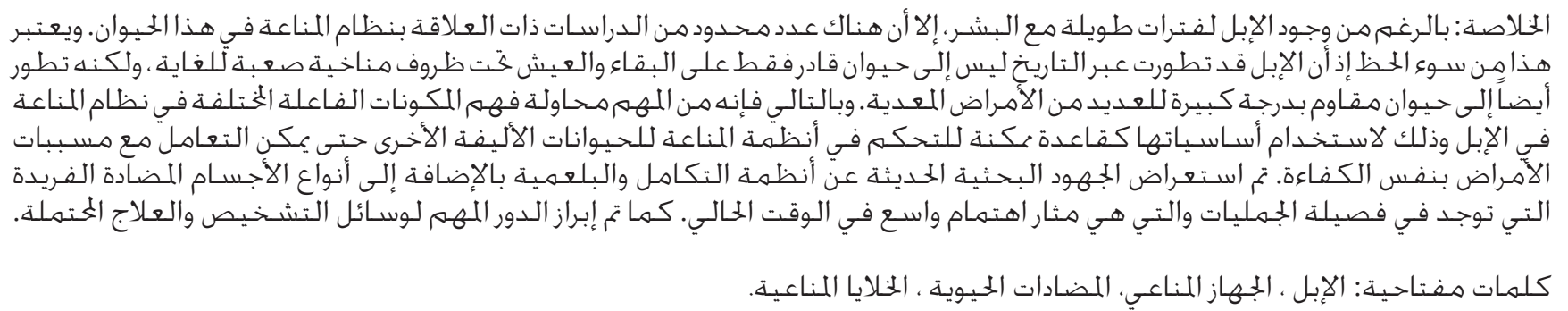

ABSTRACT: Despite the camel's long historical interaction with man there is only a limited number of studies available pertaining to the immunobiology of this species. This is unfortunate as the camel has evolved into an animal capable of not only surviving under extreme environmental conditions but also into one that is relatively resistant to a great number of infectious diseases. Accordingly, it is of interest to understand the various components operative in the camel immune system, as a potential basis of manipulating the immune response of other domesticated animals to respond to disease-causing agents in a similarly effective fashion. Recent research endeavors on the complement and phagocytic system, as well as the unique antibody types found in camelids that have seen an explosion of interest in recent times have been reviewed and their potential use as diagnostic and therapeutic tools highlighted.

Keywords: Camel, immune system, antibodies, leukocytes.

\section{Introduction}

The camel remains to a great extent an enigma shrouded in the mysteries of contemporary biology, despite centuries of man's intensive dependence on and interaction with this species. Of particular interest is the fact that not only can the camel survive under some of the most extreme environmental conditions but it also appears to have evolved into an animal with low susceptibility to a variety of diseases (Fazil and Hoffman, 1981). Undoubtedly, studies endeavoring to elucidate the immunological mechanisms utilized by camels to fight pathogenic agents might lead to important breakthroughs in our understanding of the disease process in general, and perhaps open doors of knowledge that may enhance our ability to stimulate the immune system of man and other animals to function in a similar effective manner.

The immune system is a complex network consisting of many cellular and non-cellular components which interact with each other. For simplicity, it is commonly divided into an innate (non-specific) and a specific immune system. Over the last twenty years a growing body of observations and studies have been undertaken on the camel's immune system and published in a wide spectrum of international journals. The present review is an attempt to consolidate some of the most interesting findings, in the hope that this information might encourage even more scientists to explore and exploit the immunobiology of this unique animal, and equally important, to acknowledge the fine work being undertaken by a handful of researchers in various parts of the world who are helping to bring the study of one of man's oldest companions into vogue.

\section{The Complement System}

The complement system is made up of at least twenty different proteins that are present in high concentrations in the blood and tissues. These proteins work together in a cascade fashion 
to destroy invading organisms, and equally important, to act as a signaling system for other elements of the immune system. In order to keep the complement system in check the individual complement components must be activated before they become effector molecules. This can be achieved by one of three ways. The first way is mediated through antibodies and is termed the 'classical pathway of complement fixation'. The second way is termed the alternative pathway. Finally, the complement system can be activated in a more recently-described fashion termed the lectin activation pathway (Weiss et al., 1992). The result of all three pathways is the generation of a series of effector molecules. A generated membrane attack complex (C5bC9) causes lysis of foreign organisms. The complement system also produces proteins that serve as opsonins (iC $3 b$, $\mathrm{C} 3 \mathrm{~b}, \mathrm{C} 4 \mathrm{~b}$ ), and chemoattractants (C3a, C4a and C5a) that induce acute inflammation by binding to mast cells and triggering their degranulation and subsequent release of vasoactive mediators, such as histamine. In addition, these peptides can stimulate chemokines of neutrophils, adherence to endothelial cells and enhance the respiratory burst of phagocytic cells.

Camels appear to have demonstrable levels of classical pathway hemolytic activity throughout their lives (OlahoMukani et al., 1995a) and similar to lambs (Oswald et al., 1990) and calves (Jain and Goel, 1989) appear to acquire relatively large amounts of hemolytic complement activity via colostrum. They only exhibit higher levels of classical complement activity in their sera from 1-5 years of age (Olaho-Mukani et al., 1995a). Similarly, it has been reported that camels between 3 months and one year of age have higher levels of alternative complement pathway activity in their sera than camels in the age group of five years and above (Olaho-Mukani et al., 1995b). It is unknown why the complement activity declines but it is unlikely due to the presence of conglutinins in serum, as described in cows (Kakoma and Kinyanui, 1974), as only low levels of these proteins have been found in the sera of camels (Bhatnagar et al., 1987). Interestingly, older male camels have been reported to exhibit higher levels of classical hemolytic complement activity than females of the same age group (Olah-Mukani et al., 1995a). Although one can hypothesize that this is merely a hormone related phenomenon it does not readily explain what biological function this might serve. It would be interesting to determine whether older female camels are in any way more prone to infectious agents than similar aged male counterparts. Besides for the defense against microorganisms, complement appears to be important in the control of parasitemia in camels infected with Trypanosoma evansi. Also, it has been suggested that the decreased levels of complement activity commonly observed in animal trypanosomiasis might result in immunosuppression (Ouma et al., 1997).

\section{The Neutrophil}

Polymorphonuclear neutrophils play a crucial role in the phagocytosis and killing of invading microorganisms.
They are also the predominant leukocyte type found in the peripheral blood of camels (Abdurahman et al., 1992; Wernery, 1995). In camels their numbers vary with age. Young camels tend to have larger numbers of white blood cells and a higher percentage of neutrophils than lymphocytes (Wernery et al., 1999). This is in contrast to most ruminants that have a neutrophil:lymphocyte ratio approximating 1:2. The neutrophils of camels are reported to be smaller than those from other animal species (Ali et al., 1989). A unique ultra-structural observation in the camel, not found in other animal species, is the finding that the nucleus is bound by a well-defined perinuclear space (Ali et al., 1989). Camel neutrophils appear to have highly electron dense and less dense granules that likely correspond to the primary and specific granules reported in most other animal species (Ali et al., 1989). Tertiary granules have not been demonstrated. Camel neutrophils exhibit an oxidative respiratory burst similar in its kinetics to that of neutrophils of other species against Staphylococcus aureus (Cooray et al., 1997) However, our lab has observed that neutrophils from camels exhibit a higher level of activity in their chemiluminescence response than sheep (Johnson et al., 2006).

\section{The Eosinophil}

Eosinophils are most commonly associated with the ability to kill multicellular parasites and for their role in specific types of allergic reactions. However, eosinophils play an important role in regulating inflammation by modulating the function of mast cells, basophils and eosinophils (Gleich and Adolphson, 1986). They also produce inflammatory mediators such as leukotriene C4 (Jorg et al., 1982; Shaw et al., 1984), platelet activating factor (Lee et al., 1984), oxygen free radicals (Tauber et al., 1976) and cationic proteins (Olson et al., 1977; Peterson et al., 1986; Peterson and Venge, 1983). There is evidence that eosinophils might express major histocompatibility antigens after stimulation by granulocyte-macrophage colony stimulating factor (Weller, 1992). Accordingly, they might play a role in antigen presentation. Neither a structural nor functional biological equivalent to $\mathrm{IgE}$ has been found in the camel, so it is unknown whether the camel eosinophil has an Fc receptor for this or any of the three camel IgG subclasses. At the ultra-structural level the camel eosinophil has unique characteristics. Their specific granules exhibit the basic structure of an electron-dense crystalloid core surrounded by a lighter, homogenous matrix. However, in contrast to other animal species, they are very polymorphic. The crystalloid cores are extremely variable in shape and size and often segmented and demonstrate a variety of lamellated patterns. Interestingly, it is not unusual to demonstrate multiple crystalloid cores in a single granule. The extreme polymorphism of the specific granules and variety of lamellated patterns differentiate camel eosinophils from those of other species (Johnson et al., 1999). Camel eosinophils also appear to be especially effective killers 
of parasites and when activated commonly reveal hypersegmented nuclei (unpublished observation). It is not yet clear how these structural differences render the camel with such an apparent efficiency in killing parasites.

\section{Camelid Antibodies}

Antibodies are generally described as protein molecules consisting of two pairs of proteins, termed heavy chains and light chains. The prototype antibody consists of an antigen binding region (Fab), made from both heavy and light chain segments, and an Fc fraction that is made entirely from the heavy chain. Antibodies are generally considered to be divalent and bi-functional. Divalency refers to their ability to bind two antigens at the same time. The bi-functionality is based on the ability of the antibody to not only bind to an antigen but also bind via its Fc portion to specialized Fc receptors found on the surface of a variety of cells such as neutrophils and macrophages. Antibodies are made by B lymphocytes, which develop and mature in the bone marrow.

Using immunoelectrophoresis, Grover et al. (1983) reported having found three types of immunoglobulins in camels, and their associated subclasses, namely $\operatorname{IgG} 1$, $\operatorname{IgG} 2, \operatorname{IgA}$ and $\operatorname{IgM}$. These antibodies were also reported to be antigenically distinct from those of other farm animals and man. Ten years later Azawi et al. (1993) successfully separated immunoglobulins $\mathrm{G}$ and $\mathrm{M}$ from camel sera by ammonium sulfate precipitation, gel filtration and fast protein liquid chromatography. They did not however find IgA antibodies. Interestingly, they observed three bands in gels which reduced disulphide bonds. Two of the bands corresponded to the typically observed heavy and light chain antibody molecules but the third was thought to be unique but was not further investigated.

Hamers-Casterman et al. (1993) reported that in addition to the heterotetrameric antibodies consisting of two heavy and two light chains, described in other animal species, camelids also have a unique sub group of smaller antibodies. These were likely those observed by Azawi et al. (1993) and recognized to be unique but were not further studied. Hamer-Casterman and his group were able to demonstrate that these antibodies consisted only of heavy chains. These antibodies are now appropriately referred to as heavy-chain antibodies (HCAbs). The heavy chains, found in these antibodies, are also smaller than those of heavy chains of conventional antibodies. Their smaller size is attributed to the lack of the $\mathrm{CH} 1$ domain which functions as the anchor for the light chains. Nguyen et al. (1999) concluded that the loss of the splice consensus signal was responsible for the removal of the entire $\mathrm{CH} 1$ domain in camel IgG2a HCAbs. The variable domain is therefore joined directly to the hinge region in HCAbs. HCAbs correspond to the IgG2 and IgG3 fractions. The IgG2 fraction $(92 \mathrm{KDa}$ ) binds only to protein $\mathrm{A}$, whereas the $\mathrm{IgG} 3(90 \mathrm{KDa})$ fraction binds to protein $\mathrm{A}$ and protein $\mathrm{G}$. By differential $\mathrm{pH}$ elution IgG2 was shown to consist of two fractions IgG2a and IgG2b (Muyldermans and
Lauwereys, 1999). IgG1 consists of the classical $\mathrm{H}_{2} \mathrm{~L}_{2}$ antibodies that bind to protein A and G (De Genst et al., 2006).

HCAbs are reported to vary but can account for upwards of $75 \%$ of their circulating immunoglobulins (Nguyen et al., 1998). Of particular interest is the possibility that camels have likely two lineages of B-cells, each secreting different sets of $\mathrm{V}(\mathrm{H})$ gene segments used by four and two chain immunoglobulins (Ungar-Waron et al., 2003). Furthermore, sound evidence has been presented that the variable domains found in camel HCAbs are encoded by other genes than those of four chain immunoglobulins (Nguyen et al., 1998) and raises the likelihood that $\mathrm{V}(\mathrm{H})$ genes of HCAbs do not arise through an ontogenic process of somatic hypermutation.

Camel HCAbs, unlike the HCAbs derived from mouse myelomas or those found in human sera have been shown to be not only functional but also have some very unique characteristics. Camels for example infected with Trypanosoma evansi mount an immune response with a repertoire of antibodies consisting of conventional antibodies, as well as those made up of HCAbs (HamersCasterman et al., 1993). Camel HCAbs not only react with a wide range of antigens (Muyldermans and Lauwereys, 1999) but also interact with certain antigens differently than conventional antibodies. Camels that were immunized with bovine red blood cell carbonic anhydrase and porcine alpha-amylase developed HCAbs that acted as competitive inhibitors of these enzymes, in contrast to conventional antibodies that were incapable of binding to the enzymes' active sites (Lauwereys et al., 1998). This ability is ascribed to the difference in the antigenbinding sites of these different molecules. Whereas antigen recognition in conventional antibodies results from the interaction of antigen binding sites contained within both heavy and light chains, HCAb molecules have binding sites that are contained within a narrowly defined region of one molecule, the variable domain of the heavy chain (Muyldermans and Lauwereys, 1999). The antigen-binding site of the HCAb is a single variable domain referred to as the variable domain of the heavy chain of HCAbs (VHH) (Muyldermans, 2001; DeGenst et al., 2006; Deschacht et al., 2010). This finding has been a source of considerable interest as VHHs (15KDa) are smaller than the antigen-binding sites of conventional antibodies. Their production is easier than that of normal mammalian antibodies (Alvarez-Rueda et al., 2007). They can be cloned as fusion domains to effector proteins (Muyldermans, 2001) and expressed in bacteria resulting in quantitative larger amounts. Besides, VHH tend to retain their ability to bind to the antigens that elicited their production (Roovers et al., 2007). Of particular interest is that VHHs are able to recognize small antigenic sites that conventional antibodies cannot penetrate (De Genst et al., 2006; Paallanen et al., 2011). Examples of their potential uses include their development against the epidermal growth factor receptor (Omidfar, et al., 2007; 
Roovers et al., 2007) and nuclear poly (A) binding protein 1 (Verheesen et al., 2006). A recent study by Paalanen et al. (2011) reported on the ability of VHHs to serve as both activators and inhibitors for a protein kinase. This is of particular interest as there are ten isotypes of protein kinase $\mathrm{C}(\mathrm{PKC})$. VHHs permit the elucidation of the function of the PKCs and furthermore have potential therapeutic benefits for diseases that result from abnormal PKC signaling such as patients with type II diabetes. It has also been reported by Dumoulin et al. (2003) and Chan et al. (2008) that a camel antibody was able to inhibit the aggregation of lysozyme that is involved in the production of amyloid fibrils, such as those associated with the development of Alzheimer's and Parkinson's disease. A very exciting finding has been that $\mathrm{VHHs}$, at least in vitro, were able to inhibit the replication of poliovirus and this raises the hope that they might serve as potential antiviral compounds (Thys et al., 2010). There seems to be an inexhaustible potential for the use of camel VHHs. The DNA for the binding domains can be isolated and they can be generated through bacterial engineering (Arabi et al., 1997) or expressed in mouse cells (Nguyen et al., 2003). Other exciting prospects for these small molecules are their use in immunolabeling of targets such as tumors. They will also be more efficient at penetrating tumors and reaching their specific targets. Also, the single domain antibody might be useful in the development of anti-idiotypic vaccines (Muyldermans and Lauwereys, 1999). There is evidence that these smaller antibodies are less antigenic and thus might not initiate significant immune responses in patients. Herrera et al. (2005) reported that horse and sheep IgGs had more anti-complementary activity than camel IgGs. This is significant as anti-complementary activity is likely a chief mechanism leading to adverse reactions after administrations of heterologous IgG preparations in humans. This would make antiserum raised in camels for use against snake or insect venom serum potentially safer than that raised for example in horses (Meddeb-Mouelhi et al., 2003; Herrera et al., 2005; Harrison et al., 2006). Interesting is also the observation that camel antibodies have been reported to be less antigenic when injected into mice, and unlike horse antibodies, did not cause agglutination of human erythrocytes in vitro (Herrera et al., 2005). Camel VHHs have been reported to sense or induce conformational changes on different isoforms of prostatespecific antigen (PSA) and it was postulated that this might be of potential benefit to study PSA conformational flexibility and to differentiate different stages of prostate cancer (Saerens et al., 2004). The potential use of camelid antibodies is boundless and should help to raise the profiles of camels throughout the world.

The present review highlights some of the most interesting findings pertaining to the camelid immune system and above all is an attempt to prick the curiosity of researchers and spur them on to take note of this once dormant field of immunobiology and gain an appreciation for the immense value of this ancient friend of mankind.

\section{References}

Abdurahman, O.S., R. Cooray, and S. Bornstein. 1992. The ultrastructure of cells and cell fragments in mammary secretions of Camelus bactrianus. Journal of Veterinary Medicine A 39:648-655.

Ali, A.M., M.S. Abdo, M.M. Hassanain, and P.F. Prentis. 1989. Fine structure of the camel neutrophilic granulocytes with special reference to its function. Zeitschriftfuermikrok opish-anatomische Forschung 103:985-992.

Alvarez-Rueda, G., V. Behar, V. Ferre, M. Pugniere, F. Roquet, L. Gastinel, C. Jacquot, J. Aubry, and D. Baty, J. Barbet, and S. Birkle, 2007. Generation of llama singledomain antibodies against methotrexate, a prototypical hapten. Molecular Immunology 44:1680-1690.

Arababi Ghahroudi, M., A. Desmyter, L. Wyns, R. Hamers, and S. Muyldermans. 1997. Selection and identification of single domain antibody fragments from camel heavychain antibodies. FEBS Letters 414:521-526.

Azawi, S.M., S.D. Carter, and Z. Woldehiwet. 1993. The isolation and characterization of camel (Camelus dromedarius) immunoglobulin classes and subclasses. Journal of Comparative Pathology 109:187-195.

Bhatnagar, R.N., K.R. Mittal, T.N. Jaiswal, and V.D. Padmanaban. 1987. Levels of complement activity in sera of apparently healthy camels. Indian Veterinary Journal 64:192-195.

Chan, P.H., E. Pardon, L. Menzer, E. De Genst, J.R. Kumita, J. Christodoulou, D. Saerens, A. Brans, F. Bouillenne, D.B. Archer, C.V. Robinson, S. Muyldermans, A. Matagne, C. Redfield, L. Wyns, C.M. Dobson, and M. Dumoulin. 2008. Engineering a camelid antibody fragment that binds to the active site of human lysozyme and inhibits its conversion into amyloid fibrils. Biochemistry 47:11041-11054.

Cooray, R., O.A. Abdurahaman, S. Bornstein, O. Holmberg, and G. Astrom. 1997. Respiratory burst activity of phagocytic cells isolated from the mammary glands and blood of camels (Camelus bactrianus). Journal of Veterinary Medicine. Series B. 44:29-37.

De Genst E., D. Saerens, S. Muyldermans, and K. Conrath. 2006. Antibody repertoire development in camelids. Development and Comparative Immunology 30:187-198.

Deschacht, N., K. De Groeve, C. Vincke, G. Raes, P. De Baetselier, and S. Muyldermans. 2010. A novel promiscuous class of single-domain antibody contributes to the antigen-binding repertoire. Journal of Immunology 184:5691-5704.

Dumoulin, M., A.M. Last, A. Desmyter, K. Decanniere, D. Canet, G. Larsson, A. Spencer, D.B. Archer, J. Sasse, S. Muyldermans, L. Wyns, C. Redfield, A. Matagne, C.V. Robinson, and C.M. Dobson. 2003. A camelid antibody fragment inhibits the formation of amyloid fibrils by human lysozyme. Nature 14:783-788.

Fazil, M.A. and R.R. Hoffman. 1981. Haltung and Krankheiten des Kamels. Tieräztliche Praxis 9:389-402.

Gleich, G.J. and C.R. Adolphson. 1986. The eosinophil leukocyte: structure and function. Advances in Immunology 39:177-253. 
Grover, Y.P., Y.K. Kaura, and R.N. Srivastava. 1983. Preliminary studies on camel serum immunoglobulins. Indian Journal of Biochemistry and Biophysics 20:238240.

Hamers-Casterman, C., T. Atarhouch, S. Muyldermans, G. Robinson, C. Hamers, S. Bajyana, N. Bendahman, and R. Hamers. 1993. Naturally occurring antibodies devoid of light chains. Nature 363:446-448.

Harrison, R.A., S.S. Hasson, M. Harmsen, G.D. Laing, K. Conrath, and R.D.G. Theakston. 2006. Neutralisation of venom-induced haemorrhage by $\mathrm{IgG}$ from camels and llamas immunized with viper-venom and also by endogenous, non-IgG components in camelid sera. Toxicon 47:364-368.

Herrera, M., G. Leon, A. Segura, F. Meneses, B. Lomonte, J. Philippe, J.P. Chppaux, and J.M. Gutierrez. 2005. Factors associated with adverse reactions induced by caprylic acidfractionated whole IgG preparations: comparison between horse, sheep and camel IgGs. Toxicon 46:775-781.

Jain, A. and M.C. Goel. 1989. Studies on the activation and levels of haemolytic complement of buffalo (Bubalusbubalis). I. Classical complement pathway. Veterinary Immunology and Immunopathology 23:267277.

Johnson, E.H., D.E. Muirhead, R. Al-Busaidy, and B.E. Musa. 1999. The ultra-structural morphology of the camel eosinophil. Veterinary Journal 157:79-84.

Johnson, E.H., R. Al-Busaidy, and K. Al-Habsi. 2006. Comparative chemiluminescence response of polymorhonuclear leukocytes from camel and sheep: a preliminarystudy. First Conference of the International Society of Camelid Research and Development (ISOCARD), Al-Ain, UAE, 15-17 August 2006. p.125.

Jorg, A., W.R. Henderson, R.C. Murphy, and S.J. Klebanoff. 1982. Leukotriene generation by eosinophils. Journal of Experimental Medicine 155:390-402.

Kakoma, I. and M. Kinyanjui. 1974. Complement levels of normal cattle. Research in Veterinary Science 16:395-397.

Kamber, R., Z. Farah, P. Rusch, and M. Hassig. 2000. The supply of newborn camel foals (Camelus dromedaries) with immunoglobulin G. Schweizer Archivfuer Tierheilkunde 142:581-588.

Lauwereys, M., M.A. Ghahroudi, A. Desmyter, J. Kinne, W. Hoelzer, E. De Genst, L. Wyns, and S. Muyldermans. 1998. Potent enzyme inhibitors derived from dromedary heavy-chain antibodies. The EMBO Journal 17:35123520 .

Lee, T.C., D.J. Lenihan, B. Malone, L.L. Roddy, and S.I. Wasserman. 1984. Increased biosynthesis of plateletactivating factor in activated eosinphils. Journal of Biological Chemistry 259:5526-5530.

Meddeb-Mouelhi, F., B. Bouhaouala-Zahar, Z. Benlasfar, M. Hammadi, T. Mejri, M. Moslah, H. Karoui, T. Khorchani, and M. El Ayeb. 2003. Immunized camel sera and derived immunoglobulin subclasses neutralizing Androctonusaustralis hector scorpion toxins. Toxicon 42: 785-791.
Muyldermans, S. 2001. Single-domain camel antibodies: current status. Journal of Biotechnology 74: 277-302.

Muyldermans, S. and M. Lauwereys. 1999. Unique singledomain antigen binding fragments derived from naturally occurring camel heavy-chain antibodies. Journal of Molecular Recognition 12:131-140.

Nguyen, V.K., R. Hamers, L. Wyns, and S. Muyldermans. 1999. Loss of splice consensus signal for the removal of the entire $\mathrm{c}(\mathrm{H}) 1$ domain of the functional camel $\operatorname{IgG} 2 \mathrm{a}$ heavy-chain antibodies. Molecular Immunology 36:515524.

Nguyen, V.K., S. Muyldermans, and R. Hamers. 1998. The specific variable domain of camel heavy-chain antibodies is encoded in the germline. Journal of Molecular Biology 275:413-418.

Nguyen, V.K., X. Zou, M. Lauwerey, L. Brys, M. Bruggemann, and S. Muyldermans. 2003. Heavy-chain only antibodies derived from dromedary are secreted and displayed by mouse B cells. Immunology 109:93-101.

Olaho-Mukani, W., J.N.M. Nyang'ao, J.K. Kimani, and J.K. Omuse. 1995a. Studies on the haemolytic complement of the dromedary camel (Camelus dromedarius). I. Classical pathway haemolytic activity in serum. Veterinary Immunology and Immunopathology 46:337-347.

Olaho-Mukani, W., J.N.M. Nyang'ao, J.K. Kimani, and J.K. Omuse. 1995b. Studies on the haemolytic complement of the dromedary camel (Camelus dromedarius). II. Alternative pathway haemolytic activity in serum. Veterinary Immunology and Immunopathology 46:169176.

Olson, I., P. Venge, J.K. Spitznagel, and R.I. Lehrer. 1977. Arginine-rich cationic proteins of human eosinophil granules. Laboratory Investigation 36:493-500.

Oswald, I.P., F. Lantier, and G. Bourgy. 1990. Classical and alternative pathway haemolytic activities of ovine complement: variations with age and sex. Veterinary Immunology and Immunopathology 24:259-266.

Ouma, J.O., W. Olaho-Mukani, B.E.L. Wishitemi, and S.O. Guya. 1997. Changes in classical pathway complement activity in dromedary camels experimentally infected with Trypanosomaevansi. Veterinary Immunology and Immunopathology 57:135-140.

Omidfar, K., M.J. Rasaee, S. Kashanian, M. Paknejad, and Z. Bathaie, Z. 2007. Studies of thermo-stability in Camelus bactrianus (Bactrian camel) single-domain antibody specific for the mutant epidermal-growth factor receptor expressed by Pichia. Biotechnology and Applied Biochemistry 46:41-49.

Paalanen, M.M., E. Ekokoski, M. El Khattabi, R.K. Tuominen, C.T. Verrips, J. Boonstra, and C. Blanchetot. 2011. The development of activating and inhibiting camelid $\mathrm{VHH}$ domains against human protein kinase $\mathrm{C}$ epsilon. Journal of Pharmaceutical Science 42:332-339.

Peterson, C.G.B., V. Skoog, and P. Venge. 1986. Human eosinophilic cationic proteins (ECP and EPX) and their suppressive effects on lymphocyte proliferation. Immunobiology 171:1-13. 
Peterson, C.G.B. and P. Venge. 1983. Purification and characterization of a new cationic protein-eosinophil protein-X (EPX) from granules of human eosinophils. Immunology 50:19-26.

Roovers, RC, Laeremans T, Huang L, De Taeye S, Verkleij AJ, Revets H, de Haard HJ, van Bergen en Henegouwen PM. 2007. Efficient inhibition of EGFR signaling and of tumor growth by antagonistic anti-EFGR nanobodies. Cancer Immunology and Immunotherapy 56:303-317.

Sarens, D., J. Kinne, E. Bosmans, U. Werenery, S. Muyldermans, and K. Conrath. 2004. Single domain antibodies derived from dromedary lymph node and peripheral blood lymphocytes sensing conformational variants of prostate-specific antigen. The Journal of Biological Chemistry 279:51965-51972.

Shaw, R.J., O. Cromwell, and A.B. Kay. 1984. Preferential generation of leukotriene $\mathrm{C} 4$ by human eosinophils. Clinical and Experimental Immunology 56:716-722.

Thys, B., L. Schotte, S. Muyldermans, U. Werenery, H. Hassanzadeh-Ghassabeh, and B. Rombaut. 2010. In vitro activity of single domain antibody fragments against poliovirus. Antiviral Research 87:257-264.

Ungar-Waron, H., R. Yagil, J. Brenner, R. Paz, N. Partosh, C. Van Creveld, E. Lubashevsky, and Z. Trainin. 2003. Reactions of peripheral blood mononuclear cells
(PBMC) of camels with monoclonal antibodies against ruminant leukocytes. Comparative Immunology. Microbiology and Infectious Diseases 26:137-143.

Verheesen, P., A. de Kluijver, S. van Koningsbruggen, M. de Brij, H.J. de Haard, G.J. van Ommen, S.M. van der Maare and C.T. Verrips. 2006. Prevention of oculopharyngeal muscular dystrophy-associated aggregation of nuclear poly-A binding protein with a single-domain intracellular antibody. Human Molecular Genetics 15:105-111.

Weiss, W.I., K. Drickamer, and W.A. Hendrickson. 1992. Structure of a C-type mannose-binding protein complexed with an oligosaccharide. Nature 360:127134.

Weller, P.F. 1992. Cytokine regulation of eosinophil function. Clinical Immunology and Immunopathology 62, Supplement:S55-S59.

Wernery, U. 1995. Blutparameter and Enzymwert von gesunden und kranken Rennkamelen (Camelus dromedarius). Tieraertzliche Praxis 23:187-191.

Wernery, U., M.E. Fowler, and R. Wernery. 1999. Color Atlas of Camelid Haematology. Blackwell Wissenschafts-Verlag. Berlin. 37-43.

Received: March 16, 2013

Accepted: November 12, 2013 